https://doi.org/10.48009/1_iis_2005_217-223

\title{
MARKETING ON THE INTERNET: AN ONLINE COURSE TO MERGE E-MARKETING THEORY AND SYSTEMS DEVELOPMENT
}

\author{
Marc D. Miller, Ph.D., Augusta State University, mmiller@aug.edu \\ Barbara C. Coleman, Ph.D., Augusta State University, bcoleman@aug.edu
}

\begin{abstract}
This paper reports on the design and deployment of an online course which merges e-marketing theory and development of systems to facilitate e-marketing strategies. This course is taken by marketing majors at a mid-sized university. This course has the overall objective of delivering hands-on technology skills to the marketing major.
\end{abstract}

Keywords: online learning, e-marketing, e-commerce, pedagogy

\section{INTRODUCTION}

The knowledge, skills, and abilities required of marketing students entering the work force have rapidly shifted to include the goal of being more competent with information technology (IT) tools that help solve marketing problems $[3,5,7,8]$. For example, the marketing student must have an awareness of how technology facilitates the marketing process. Moreover, in many cases the graduate will be expected to be a key player in the analysis, design, and deployment of computer information systems that enable the effective marketing of goods and services. Similarly, as the business environment becomes more firmly entrenched in the information age, the skill sets that are required of all business students will include the ability to deploy technology within their functional areas. Unfortunately, the marketing curriculum is typical of the other business majors in that it includes a number of courses that address the topics of information technology (IT) use, but offer students little or no hands-on experience in actually developing and deploying marketing information systems. Therefore, the abstract nature of topics such as Customer Relationship Management (CRM), database marketing, e-mail management, and other Internet based marketing tools is difficult for the student to visualize and apply.

Mitchell \& Strauss [7] have identified thirteen key skills that are currently being discussed in emarketing and e-commerce courses. The top five skills are 1) web-page design, 2) information architecture, 3) database design and transaction management, 4) programming page interactivity, and 5) database marketing and relationship management. The problem that devolves from the creation of their list is how best to teach the tools that are required in order to master these skills. A number of authors have proposed solutions for the need to include IT tools in the curriculum [e.g., 1, 4, 7, 8]. For example, Hannaford, et.al. [3] make a case for including actual marketingspecific issues and problems in newly developed courses so that the student can master IT skills and the theory behind them. This paper describes a new course that was designed to follow the principles outlined by Hannaford et al [3] and bridge the gap between e-marketing theory and practice. The course, which has been titled Marketing on the Internet, provides the student with interactive online lessons in the development of marketing systems that use ColdFusion, a web- 
based database server software program, and Dreamweaver, a web page development software package. The course modules give students interactive instruction in developing a marketing system for a fictional real-estate firm. The student is taken through a three step marketing process: 1) collecting customer data, 2) creating CRM systems which match customer preferences to current real estate listings, and 3) developing target marketing systems using email as the medium of delivery. The strength of the course rests with its ability merge theory, as it relates to using information systems as part of the marketing function, with actual practice in developing and deploying these systems via a commercially used product.

\section{CONTENT AND ORGANIZATION OF THE COURSE}

The course is comprised of three basic sections: 1) Basic Tools, 2) Advanced Tools, and 3) Concepts. The basic tools section is a pre-requisite for the Advanced Tools section, while the Concepts section is completed throughout the semester.

\section{Basic Tools}

The basic tools section gives students an essential understanding of databases and how SQL can be used to Create, Read, Update, and Delete data from the database. In addition, students are shown how to create ColdFusion webpages which can interact with the database to accomplish these basic database objectives. There are four modules in this section: Introduction to SQL (Structured Query Language), Introduction to Dreamweaver, Introduction to ColdFusion Parts I and II.

\section{Introduction to SQL}

This module exposes the student to the basic syntax of Structured Query Language. The student is first given introductory information about how SQL works with relational databases. Then the student is taken through the process of reading, writing, and updating data within SQL. That is, the student is expected to understand the SELECT statement and WHERE clause, the INSERT INTO, and UPDATE statements. This knowledge is then built upon in the later modules, Introduction to ColdFusion I and II modules.

\section{Introduction to Dreamweaver}

This module exposes the student to the basic framework and windows of Dreamweaver MX. It provides the student with a basic understanding of how this software works in conjunction with ColdFusion. One of the more challenging aspects of this course is to communicate to the student that ColdFusion is a server software and that one rarely interacts directly with it, but rather through Dreamweaver. Therefore, this module attempts to show this interaction.

\section{Introduction to ColdFusion Part I and II}

These modules further expose the student to the interaction between Dreamweaver and ColdFusion. The interactive modules give the student an understanding of how to read, write, 
and update the database. The modules use a simple list of video movies in which the student is shown how to extract the list from the database and then format the list into an HTML table. Further, the student creates a page where the user can ask to show the list by a particular year that the movie was released. The second part shows the student how to add a record to the database, edit a record, and then delete a specific record from the database. The student is then given a similar assignment in which he is working with a list of books. The student then creates a set of webpages that will list the books by year and author, add a new book, edit a record, and delete a record from the database.

\section{ADVANCED TOOLS}

The advanced modules provide students with a simulation that creates a marketing information system for "Garden City Real Estate." This real estate firm starts off by collecting demographic data concerning the advertising effectiveness of their website. The data are then extracted from the database to a spreadsheet "on the fly" for analysis by the firm. In subsequent modules, students are shown how to collect more specific data from customers regarding their real-estate needs (i.e., price range, location, and features). They are then shown how to customize the webpage depending on each client's preferences. Finally, the system then matches the client's needs to current real-estate listings and generates an automatic email when a new listing meets the client's needs.

The modules are presented through interactive lessons that first take an overview approach to show the students the flow of the objectives. For example, in the first module the student is shown how to create a pop-up online survey and then to see the results in an Excel spreadsheet. This will take four webpages: the homepage of the site, the pop-up survey, the page which will process the data and tell the user that her survey responses have been recorded, and the page to output the results in Excel. Therefore, the beginning of the module provides an overview before beginning to work on the specific pages.

The modules then take the student through the process of creating the specific webpages in a step-by-step approach with explanation. The simulations created for the modules are very realistic with one notable exception: They cannot click anywhere but in the area that is called for in the instruction/explanation. Therefore, the student cannot deviate from the steps required to accomplish the objectives. The course includes the following advanced modules: Advanced ColdFusion Part I: Creating an Online Survey, Advanced ColdFusion Part II: Registration and Login Tools, Advanced ColdFusion Part III: Online Survey Part II, Advanced ColdFusion Part IV: Dynamic Content, Advanced ColdFusion Part V: Sending a Data Driven E-Mail

\section{Advanced ColdFusion Part I: Creating an Online Survey}

As noted earlier, the learning objectives of this module are to create a process by which data are gathered on how the visitor found this website. Further, a tool is created to download the data directly into a spreadsheet for analysis. The student is first shown how to use tools in Dreamweaver that create a survey window that automatically pops up, and then how to create the tools to update the database with ColdFusion. Throughout, the synergy between the development tool and the server software is explained and illustrated. The student is then given the assignment 
for developing a similar (but not exact) set of webpages for a fictional antique car brokerage firm.

\section{Advanced ColdFusion Part II: Registration and Login Tools}

The second module has the basic learning objective of creating a set of pages that establish a login and registration. This information is then used to customize the user's web-page by including their name on the page. The student then completes a similar assignment by continuing with the car broker.

\section{Advanced ColdFusion Part III: Online Survey Part II}

This module builds on Advanced Module 2 in which the student was shown how to develop a basic login and client registration form. The user logs into the webpage and her first and last names are displayed on the screen. In this module, we carry this concept a bit further as the student is shown how to create another online survey which collects specification data on the client. Specifically, data are captured on the user's real estate needs. That is, we want to know if the user is searching for commercial or residential properties, the price range, and preferred geographic regions. Finally, the student is shown how to dynamically graph data in order to assist in the user's analysis.

\section{Advanced ColdFusion Part IV: Dynamic Content}

This module shows the student how to create dynamic WebPages that are specifically designed to change in response to the client's specifications. The overall objective is for the user to see real estate listings that meet their needs. Hence, the student is shown how to create queries that match together the needs of the client with our current listings. In addition, structures are developed o identify what will happen if the database does not have any listings that match current client preferences. The student assignment is again similar in nature to the module.

\section{Advanced ColdFusion Part V: Sending a Data Driven E-Mail}

In the final module, the student is shown how to create a system that will first allow the user to enter a new real-estate listing. In addition, after the new listing has been entered, the system will match the listing against client preferences and produce a list of clients that might be interested in this new listing. Finally, using this query output, we show the student how to build a tool that will automatically send an e-mail to the client alerting her to this new listing. The student's final assignment emulates the module example.

\section{CONCEPTUAL MODULES}

In addition to basic application tools, the course also introduces students to important Internet marketing concepts. Students must work through the following eight modules, each of which includes readings, notes and quizzes. Students work on the modules throughout the course. That is, the student will be referred to a conceptual module as the relevancy arises during the technical modules. Therefore, the student is able to see the direct connection between marketing theory 
and practice. The readings are available either online or through the university library system. The video vignettes are available from CNET.com.

The conceptual modules include the following lesson areas:

- Introduction to Marketing on the Internet

- Customer Experience

- Online Communities

- Database Marketing

- Customer Relationship Management

- Clickstream Technology

- E-Mail Management

- Online Advertising

\section{PRESENTATION OF THE COURSE}

This course uses a course management system (CMS) that assists the instructor in delivering and managing the course materials. Each week the CMS indicates where students should be in the mastery of course objectives and approximately how much time should be spent on each module. The student can see his progress in relationship to the weekly standard through the Student Dashboard. The instructor enters the course standards through the instructor menu of the CMS. These standards, as presented to the student through the Dashboard, give the student a benchmark as to their progress.

The CMS system also gives the instructor a means to monitor the progress of each student and to give weekly feedback for reinforcement. Each Friday, the CMS sends the student an e-mail that takes data from the student records and matches it to the weekly progress standard. The instructor is notified of students who are falling below current standards. These students are asked to come to the computer lab where the student can work one-on-one with an instructor or a graduate assistant trained in the modules.

\section{EFFECTIVENESS}

As the primary objective of this course was to merge e-marketing theory with practice, the primary measure of effectiveness is to examine student ability to complete the stated assignments using Dreamweaver and ColdFusion. Evaluation of the student's ability to meet this objective is through three primary factors. First, the total amount of time spent in the modules is monitored and evaluated. Second, the student's performance on the quizzes is monitored. Finally, the grades the student receives on the assignments are used to monitor student achievement of the learning objectives.

The student is expected to spend at least 50 minutes per week in the modules. However, this number will vary greatly. Some students can grasp the module concepts with somewhat less effort, while others take significantly more time in the modules. The average amount of time spent in the modules during the current semester is 87 minutes. The maximum amount time spent 
during any particular week was 343 while the low was 22 . Measuring seat time in front of the CMI modules is far from a perfect measure of student comprehension. However, it does help to indicate the amount of effort an individual student is exerting in attempting to learn the course materials. For example, when a student indicates that he is having trouble with a particular concept, the instructor will first check the amount of time spent in the modules. If no or little time has been logged in working with the modules, then the instructor knows that the student needs to start with fundamental concepts versus trying to master a more complex issue.

The quizzes are a more objective measure of progress in mastering course content. In the current semester, the average quiz grade is 70 . The maximum grade is 100 while the lowest grade is 30 . The quiz grades show strong correlation with the amount of time spent in the modules $(\alpha=.88)$. That is, the more time a student spent working through the interactive lessons, the higher the grade that the student received. The quizzes are a multiple choice-type format and are given online. Again, the quiz grades are not a perfect measure of objective achievement. However, the quizzes do give feedback to the student on what areas they are or are not mastering.

Finally, the student assignments are evaluated to measure objective achievement. The grades assigned to individual assignments can vary from $100,85,75$, to 0 . A 100 would indicate achievement of assignment objectives while the 85 or 75 would indicate partial achievement. Currently, the mode of the grade distribution is 85. Again, assignment grades and the time spent in the modules are highly correlated $(\alpha=.76)$. However, the correlation between time and assignment grades is less strong than the correlation between time and scores on quizzes. The lower correlation may be a function of some individual students who may require less time to comprehend the modules and complete the assignments than other students.

Overall, students have been highly satisfied with both the course delivery method and the course content. The delivery method gives students the flexibility to complete the course materials when and where they wish. Many students (65\%) work directly from home while others work exclusively from the computer labs on campus.

The course content has also met with high levels of satisfaction. When asked for comments about the course, many students indicated that while the materials were challenging they could see that they were developing skills that would give them employment marketability. Other students indicated that they would definitely recommend this course to their friends and believed that it would give them an edge in the job market.

\section{CONCLUSION}

As stated in the introduction, the overall objective of this course is to merge e-marketing theory with practice. Students are given instruction on how to create and deploy database driven websites that fulfill the basic functions of the marketer. In addition, students are shown how the development of the marketing tools relates to current marketing theory as expressed in the literature. The overall effect is to provide technology skills that are couched within a specific marketing function. The effect on student outcomes is to produce a marketing professional who not only understands the need for technology driven marketing strategy, but who also knows how to create them. 


\section{REFERENCES}

1. Benbunan-Fich, R., Lozada, H. R., Pirog, S., Priluc, R., \& Wisenblit, J. (2001). Integrating Information Technology into the Marketing Curriculum: A Pragmatic Paradigm. Journal of Marketing Education, 23(1), 5-16.

2. Evans, J.R. (2001). The Emerging Role Of The Internet In Marketing Education: From Traditional Teaching To Technology-Based Education. Marketing Education Review, 11(3), $1-15$.

3. Hannaford, W., Erffmeyer, R. \& Tomkovick, C. (2002). Championing Technology In Marketing Education: Assessing The Value Of A Discipline-Specific Technology Course. Marketing Education Review, 12(3), 47-58.

4. Kaynama, S.A. \& Keesling, G. (2000). Development of a Web-Based Internet Marketing Course. Journal of Marketing Education, 22(2), 84-90.

5. McCorkle, D.E., Alexander, J.F., Reardon, J. (2001). Integrating business technology and marketing education: Enhancing the diffusion process through technology champions. Journal of Marketing Education, 23(1), 16-25.

6. Miller, F. \& Mangold, W.G. (1996). Developing Information Technology Skills In The Marketing Curriculum. Marketing Education Review, 6(1), 29-40.

7. Mitchell, T. \& Strauss, J. (2001). Practitioner and Academic Recommendations for Internet Marketing and E-Commerce Curricula. Journal of Marketing Education, 23(2), 91-103.

8. Sterngold, A.H. \& Hurlbert J. M. (1998). Information Literacy and the Marketing Curriculum: A Multidimensional Definition and Practical Application. Journal of Marketing Education, 20(3), 244-250. 